\title{
Experimental and CFD Investigations on Compartment Explosion with Ignition and Fuel Sources Located in Different Compartment
}

\author{
TADASHI KONISHI \\ Department of Mechanical Engineering \\ Oita National College of Technology \\ 1666 Maki \\ Oita, 870-0152, Japan
}

\begin{abstract}
In order to elucidate a complicated accident of boat explosion, experimental and CFD investigations by using a 2-D small-scale chamber and a 3-D large-scale mock-up model are demonstrated. In case that a chamber is divided into several compartments having different locations of ignition and fuel sources, the explosion process becomes more complicated. In our 2-D chamber with three compartments, flame nucleus is initially established in the ignition compartment and propagates at the laminar flame velocity. After the spreading flame erupts through a narrow gap into next compartment, flame becomes turbulent and accelerates. As a result, the premixed combustion happened in the ignition compartment, but did not give significant pressure rise due to a low value of laminar burning velocity. The mock-up model and CFD model are used for verifying the actual boat explosion. The flammable limit of gasoline vapor in the ignition compartment is established in the 1.7th day to the 175th day since fuel was leaked from the fuel-source compartment. The experiments on vapor diffusion process are also compared with CFD results. The calculated concentration profiles on 2D and 3D model are fairly good agreements with the results of the experiments. Finally, the reproducibility test of the boat explosion was successfully carried out by the mock-up boat.
\end{abstract}

KEYWORDS: compartment explosion, vapor diffusion, mock-up model, CFD

\section{INTRODUCTION}

Explosion is produced by rapid energy release and causes severe accidents by blast wave, radiation and dispersion of debris. Explosion can be divided roughly into the rapid combustion in enclosed volume and one in open volume. In enclosed volume, since little attenuation of pressure wave and turbulence intensity is achieved, the detonation occurs easily. For this reason, it is expected that most exothermic energies produced by the combustion reaction can be converted into explosion energy. Even though the detonation does not occur, breakage of the enclosed chamber with high proof pressure produces strong explosion. On the other hand, pressure buildups by explosion are not observed in the fully opened volume. It is because the pressure release by pressure wave propagating at sound velocity contradicts promptly the pressure buildup by expansion of the gas produced by exothermic reaction. In cases where two or more compartments are connected in the pipe, and the enclosed chamber are divided with partitions having small holes, the explosion process becomes more complicated. Investigations have been made on explosion transmission through a channel or a gap from a vessel to another vessel [110]. The explosion transmitting between linked chambers is characterized by increasing the initial pressure and density in the second chambers, which is called "pressure piling". Many researchers investigate the "pressure piling" for the effect of geometry and 
dimension of connected chambers. Unfortunately, the results of above quoted works did not mention the large or middle scale explosion between linked chambers. Bradley et al. [11] only reported explosion and flame acceleration due to flame-induced instabilities in large vented box structures. In addition to compartment explosion, the aircraft explosions were investigated by Sochet et al. and White et al. [12,13]. They especially focused on the relation of the explosion with flame spread and flammability of aviation fuels. This paper describes an experimental and CFD analysis on explosion mechanism by using both of the small-scale and large-scale linked compartments. Although several possible scenarios are considered in the explosion, two feasible scenarios are given. Gasoline vapour diffuses from the tank compartment, where the gasoline is spilled from the fuel tank, to the battery compartment. The vapour ignited by the spark in the battery chamber and the flame propagated through the drainage from the battery chamber to the body of the boat. Another scenario is given that the leak of spilt earlier fuel in the body of the boat through drainage, where it evaporated. The ignition occurs by a certain manner (e.g., static electricity) in the body. The study focuses on diffusion process of fuel vapor from the fuel compartment to the ignition compartment and determines the attainment time to reach flammable limits of fuel vapor at the ignition compartment. Flame propagating process is also exhaustively investigated by using 2-D chamber explaining the flame propagation process from the ignition compartment to other linked compartment.

\section{OUTLINE OF BOAT EXPLOSION ACCIDENT}

As shown in Fig. 1a, the boat has an overall length of $560 \mathrm{~cm}$, a maximum width of $178 \mathrm{~cm}$, and a height of $72 \mathrm{~cm}$ (bow), $50 \mathrm{~cm}$ (center) and $54 \mathrm{~cm}$ (stern). The boat was constructed from fiber-reinforced plastics and the fuel tank was made from iron. The boat was built and purchased in 1991. In 1993, the rusty fuel tank was replaced and used for 11 years until the day of explosion accident in March, 2001. Then, several drainage holes were bored in the partitions of the boat chambers in order to draw out seawater accumulated in the bottom of the work deck chambers. As a result, the passages of gasoline vapor were completed from the compartment $\mathrm{A}$ to the compartment $\mathrm{B}$ via the compartment C. Therefore, when gasoline vapor continuously leaked from the fuel tank, a large amount of gasoline vapor is expected to be accumulated in the compartment $\mathrm{C}$ and B. On the day of the accident, 4-liters of gasoline were supplied to the fuel tank equipped in the compartment $\mathrm{A}$. The gasoline had not spilt outside the fuel tank under supplying of the gasoline. When the starter button of the outboard motor was pressed 2 or 3 times in order to move the boat, the explosion immediately occurred. This explosion completely destroyed the compartment $\mathrm{C}$ and $\mathrm{D}$, however, the compartment $\mathrm{B}$ and $\mathrm{A}$ were not damaged. The investigation of the boat accident was expected to reveal the explosion mechanism. 

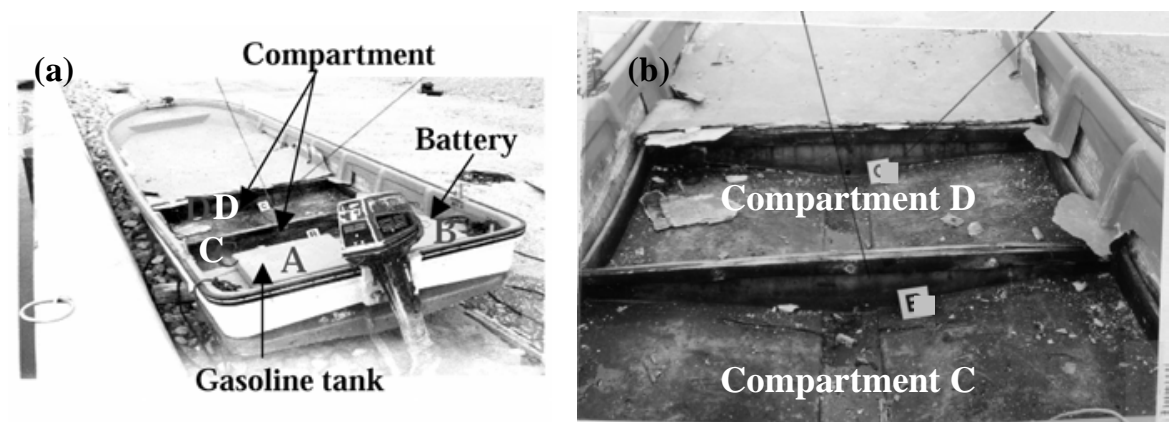

Fig. 1. Photographs of the damage made by explosion to the boat, for the whole view (a) and the exploded compartment (b).

\section{TWO-DIMENSIONAL COMPARTMENT EXPLOSION}

\section{Small-Scale Combustion Chamber}

The photograph and schematic illustration of a small-scale combustion chamber is shown in Fig. 2. The combustion chamber has three compartments; the compartment A has the fuel-source, the compartment $\mathrm{B}$ has the ignition-source and the compartment $\mathrm{C}$ has the empty volume. The dimensions of each compartment are $100 \mathrm{~mm}$ wide, $100 \mathrm{~mm}$ high and $160 \mathrm{~mm}$ long. The chamber was constructed by an aluminum plate with a thickness of $10 \mathrm{~mm}$. The observations of ignition and flame behavior are accomplished through a $10 \mathrm{~mm}$-thick glass plate prepared in the front of chamber. In order to prevent the glass breakage from an explosion, three openings (each $25 \mathrm{~cm}^{2}$ ) were prepared at the top of the combustion chamber for each compartment. The paper covers pasted to the openings of the compartment B, C and the compartment A was covered by an aluminum plate. In Fig. 2, the passage I (5 mm-clearance in the upper part) connects chamber A and B via chamber $\mathrm{C}$ and the passage II (10 mm-clearance in the lower part) connects the chamber $\mathrm{A}$ and $\mathrm{B}$ directly. A fuel container was made from Pyrex glass and the dimension was $10 \mathrm{~mm}$ wide, $30 \mathrm{~mm}$ deep and $150 \mathrm{~mm}$ long as described in our previous paper [14-16]. An ignition device was assembled with a dc-battery, a distributor and an ignition plug of an automobile. The fuel used was n-hexane.

(a)

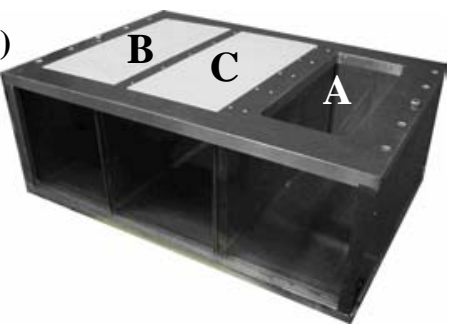

(b)

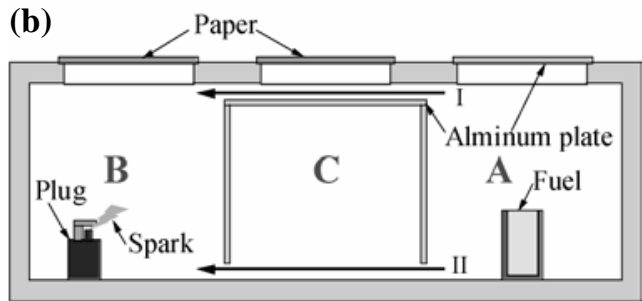

Fig. 2. The photograph (a) and schematics illustration (b) of a small-scale combustion chamber. 


\section{Diffusion of Vapor from Fuel-source Compartment to Ignition-source Compartment}

Diffusion behaviors were visualized by holographic interferometry (HI). Holographic interferometry is based on refractive-index changes in the gas phase that are due to species concentration variation. The detail analysis of holographic interferometry can be found in Ref. 17. Figure 3 shows the experimental and CFD concentration profiles of nhexane. The CFD results are arranged in left row. The interferogram pictures are arranged in right row. The concentration profiles measured by HI are compared with CFD results are indicated by gray dashed line in Fig. 3 . The gray dashed line shows 1.2 vol.\% i.e., lean flammable limit of $n$-hexane. The calculated concentration profiles at 5 and 10 second after fuel-release are fairly good agreements with the results of the experiments. At 30 seconds after fuel-release, fuel vapor diffuses faster that predicted. In compartment $\mathrm{C}$ and $\mathrm{B}$, CFD results are lower than that of the experiments, which indicate convection term in CFD induced by evaporation might be underestimated. Due to the limited range in field of view, the interferograms are out of view after 1 minute or later.
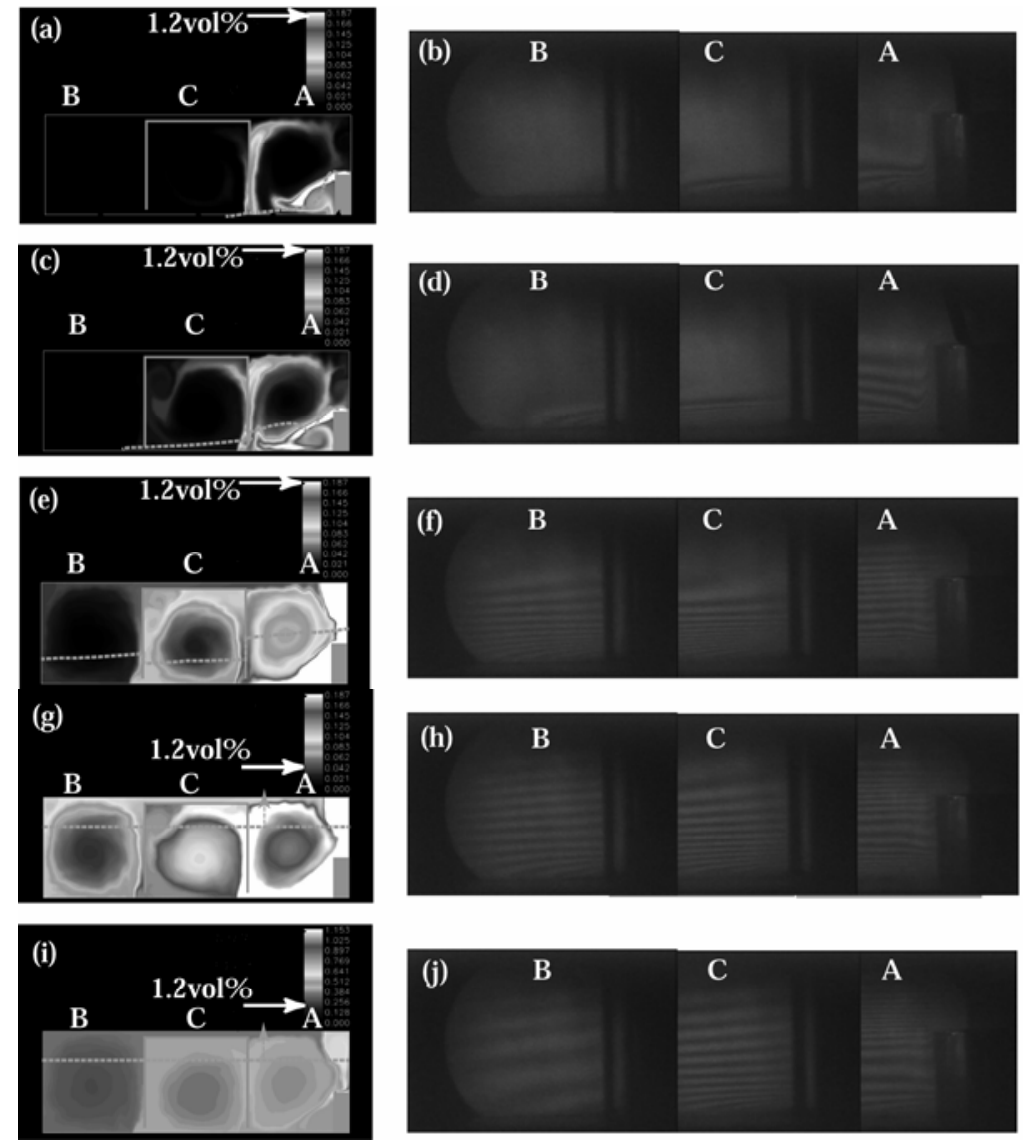

Fig. 3. Concentration profiles of n-hexane vapor evaporated from fuel tray. CFD results (left row) and interferogram pictures (right row) are represented at 5 seconds (a),(b), $10 \mathrm{sec}(\mathrm{c}),(\mathrm{d}), 30$ seconds (e),(f), $60 \mathrm{sec}(\mathrm{g}),(\mathrm{h}), 3$ minutes (i),(j), respectively. The gray dash lines in left figures indicated 1.2 vol.\% i.e., lean flammable limit of n-hexane measured by HI are compared with CFD results. 
The behaviors of ignition and flame propagation phenomenon were verified by the smallscale combustion chamber as shown in Fig. 4. At the beginning, the flame nucleus was formed around the ignition plug at $2 \mathrm{~ms}$ after spark ignition. The diameter of flame nucleus increases with time. The flame speed is reached in range from $2 \mathrm{~m} / \mathrm{s}$ to $5 \mathrm{~m} / \mathrm{sec}$ at the beginning of the flame propagation. The laminar flame propagation may be established. The flame was transmitted from the compartment B to C through the $5 \mathrm{~mm}$ clearance between the two compartments in Fig. 4b. When the flame propagated from compartment $B$ to the compartment $C$, flame-spread rate increased from 10 to $20 \mathrm{~m} / \mathrm{s}$. The turbulent flame was considered to establish, when the flame passed through the clearance. As the flame speed increases rapidly and finally caused the explosion. The explosion deformed the partition between the compartment $\mathrm{C}$ and $\mathrm{A}$, but the paper openings, which were adhered to the top of the compartment $\mathrm{B}$ and $\mathrm{C}$, were not damaged as shown in Fig. 4d. On the other hand, the aluminum board, which was placed on the upper part of the compartment A, was blown away by the explosion. Fairweather et al.[1] reported the studies of premixed flame propagation in a cylindrical vessel with two internal obstacle baffles. They concluded that flame propagation through the vessels was found to be substantially laminar until the flame encountered the first obstacle. The significant overpressure generated in the later stages of explosions due to rapid turbulent combustion in the shear layers and recirculation zones induced by the obstacles. In our experiments on the small-scale combustion chamber, as the jet like flame was discharged from $5 \mathrm{~mm}$ clearance, it may induce the recirculation in chamber C. As Fairweather et al. pointed, it gives rise to overpressures in chamber $\mathrm{C}$.
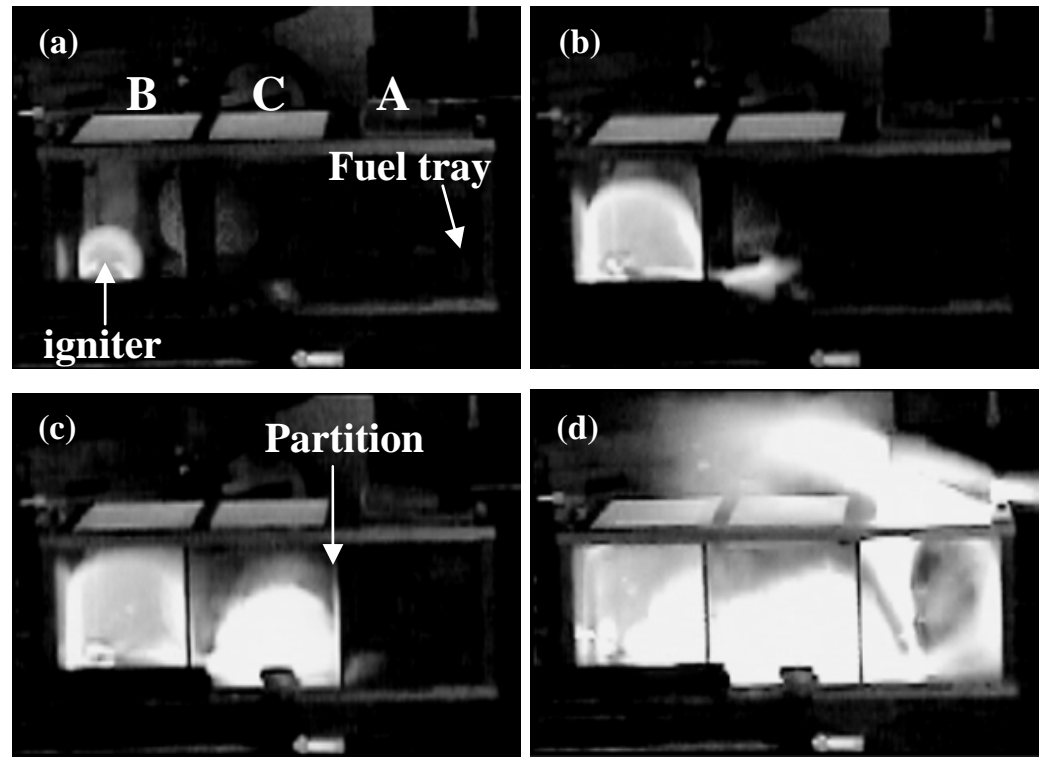

Fig. 4. Photographs show the behavior of ignition and flame propagation for gasoline vapor in the combustion chamber. The elapsed time from spark ignition is $12.5 \mathrm{~ms}$ (a), $25 \mathrm{~ms}$ (b), $29.2 \mathrm{~ms}$ (c) and $37.5 \mathrm{~ms}$ (d). 


\section{Large-Scale Wooden Mock-Up Boat}

The photographs of a mock-up boat are shown in Fig. 5. The mock-up boat was constructed from $12 \mathrm{~mm}$ thick plywood board. The size of the mock-up boat was $224 \mathrm{~cm}$ long, $159 \mathrm{~cm}$ wide and $50 \mathrm{~cm}$ high. A fuel tank and a dc-battery were placed in compartment $\mathrm{A}$ and $\mathrm{B}$, respectively. The gasoline vapor may leaked from the corrosion hole with about $2 \mathrm{~mm}$ in diameter in the side part and the air vent hole with $2 \mathrm{~mm}$ in diameter located in the refueling cap. The liquid gasoline may split from the rusty welding parts in the lower part. The compartment $C$ and $D$ were prepared for the work deck chambers, which were severely destroyed by the explosion. The mock-up boat is schematically illustrated in Fig. 6a. The compartment A and B are connected by passage I. The compartment $\mathrm{A}$ and $\mathrm{B}$ via the compartment $\mathrm{C}$ are connected by passage II. The locations of concentration measurement are indicated by serial numbers for each compartment. Nine locations for compartment A, B and D and ten for compartment C are prepared for measuring. Two different heights of concentration measurement are conducted for each location at $1 \mathrm{~cm}$ deep from the top board and $3 \mathrm{~cm}$ above the bottom board. The measurements are started as soon as gasoline is supplied to the fuel tank. The local concentration of gasoline vapor leaked in the boat is measured by a portable hydrocarbon gas detector (RIKEN KEIKI RI-415). The RI-415 gas detector was specifically adjusted for i-butane, the concentration of gasoline vapor was not able to measured directly. Therefore, the reading of RI-415 gas detector (for i-butane) was calibrated for that of gasoline vapor by using Reid method. Reid method is specified to JIS K2258, which is equivalent to ISO 3007 and ASTM 4953, which measures the vapor pressure of volatile crude oil, the volatile fuel oil with a gauge pressure [18].
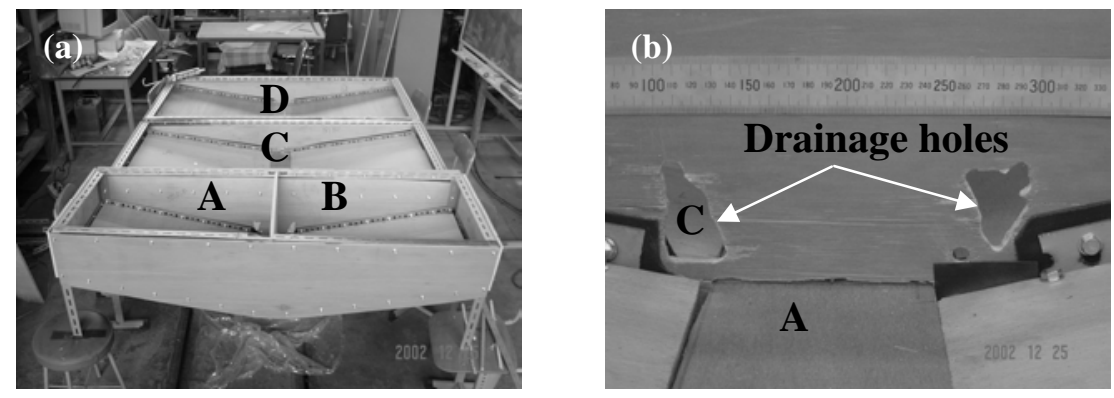

Fig. 5. The photographs of the large scale model, the whole view (a) and the partition $\mathrm{A}$ and $\mathrm{C}$ are connected through two drainages.

\section{CFD Model}

Figure $6 \mathrm{~b}$ illustrates the 3-D model of the mock-up boat. The gasoline tank is located in compartment $\mathrm{A}$, and the battery as the ignition source is settled in the compartment $\mathrm{B}$. The several holes, which connect between the compartments, are accurately constructed in the CFD model. The monitoring points of concentration in CFD model are located in the position A-8, B-2 and C-5 shown in Fig. 6a. 

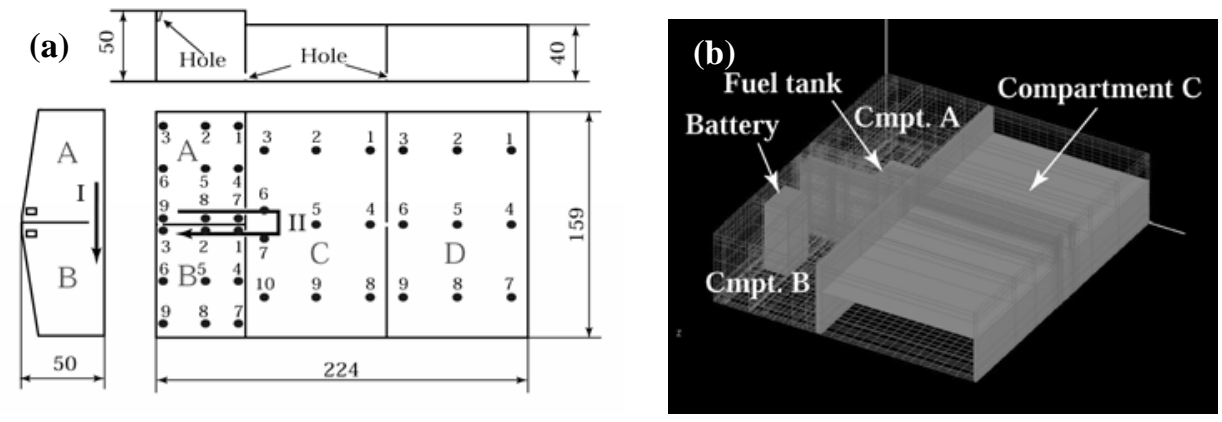

Fig. 6. The configurations of the mock-up boat and measuring points for vapor concentration were shown, nine locations for each of the chamber

A, B and D and ten for the chamber C were selected (a),

3 dimensional CFD model of mock-up boat (b).

\section{Diffusion Process of Gasoline Vapor from Fuel-Source Compartment}

The diffusion process of gasoline vapor is investigated by using the mock-up boat. The original fuel tank filled with gasoline is placed in the compartment A of the mock-up boat. The measurements of vapor concentration are conducted for every hour. In order to prevent the explosion, the measurements are suspended when the maximum concentration exceeds the lean flammable limit of gasoline vapor. In Fig. 7, the results are shown for A-8 (the position nearest to the holes of the fuel tank in the compartment A), B-2 (the position nearest to the dc-battery terminal in the compartment B), C-5 (the position nearest to the partitioning hole in the compartment C), and D-6 (the position nearest to the partitioning hole in the compartment $\mathrm{D}$ ). The horizontal axis indicates the elapsed time after the fuel tank is placed in the mock-up. The vertical axis indicates the measured vapor concentration by the percentage of lean flammable limit. The lean flammable limit of gasoline vapor is $1.2 \mathrm{vol} \%$, which corresponds to $100 \mathrm{LFL} \%$ and the upper limit is $7.3 \mathrm{vol} \%$, which corresponds to $600 \mathrm{LFL} \%$. Plotting all data on logarithmic scale, concentration curves make straight lines to the elapsed time. By extrapolating the straight line, an attainment time to reach the upper limiting can be predicted. The diffusion process of gasoline vapor can be predicted by the concentration values in each compartment. The gasoline leaked from gasoline tank in the compartment A diffused to the compartment $\mathrm{B}$ and $\mathrm{C}$ and finally reaches to the compartment $\mathrm{D}$. At the compartment $\mathrm{B}$ with ignition-source and compartment $\mathrm{C}$, the flammable range of gasoline vapor is maintained in the range from the 1.7th day to the 175th day from the day when gasoline is leaked from the fuel tank. Therefore, in this period, the compartment B and C were always exposes to the danger of explosion and the explosion might readily happen by ignition-source. Although it is not clear "how long time it took for a fuel vapour to accumulate in compartments C and D" in this accident, the explosion of the compartment $\mathrm{C}$ and $\mathrm{D}$ suggested that at least 30days have passed from the gasoline leakage. Figure 8 shows the concentration profiles of CFD results. The height of concentration monitoring plane is adjusted as the mock-up experiments i.e., $3 \mathrm{~cm}$ above the bottom board. The diffusion of fuel vapor through the lower hole between compartment A and compartment $C$ (passage I) is observed after an hour from fuel leakage. Vapor diffusion form the upper hole between compartment A and compartment B (passage II) are achieved after 6 hours from leakage. This time delay attributes to vapor density. As gasoline vapor is heavier than air, the fuel vapor easy to go below. The comparison of CFD results with the 
experiment is indicated in Fig. 7. Good agreements are obtained in compartment B after 10 hours or later from fuel leakage. However the CFD results and the experiment in compartment A were not in agreement. In compartment C, CFD results are lower than that of the experiments, which indicate convection term in CFD induced by evaporation might be underestimated.

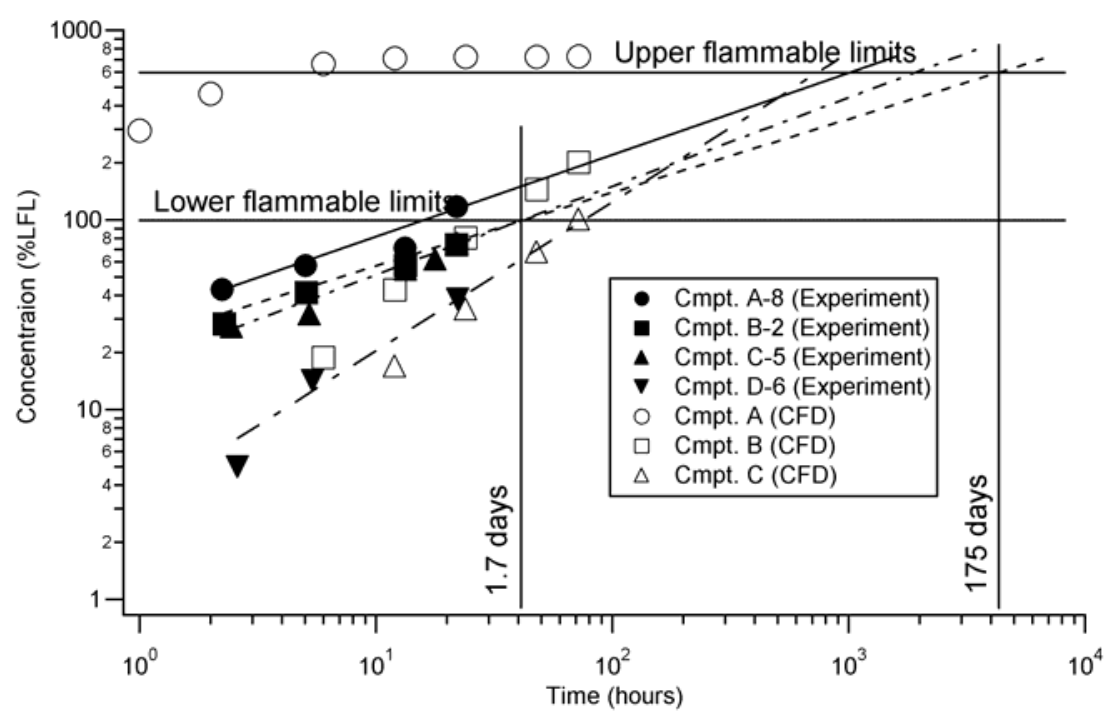

Fig. 7. The concentration profiles of both the experiments on the mock-up boat and CFD are shown for compartment A, B, C and D (except CFD).

\section{REPRODUCIBILITY TEST OF BOAT EXPLOSION}

Finally, in order to confirm the presumed mechanism of the boat explosion, a reproducibility test was carried out by using the mock-up boat under similar situation as actual accident. The reproducibility test testified that the ignition-source compartment has never exploded but the linked-compartment $\mathrm{C}$ had exploded as expected.

\section{CONCLUSIONS}

1. The compartment explosion mechanism can be elucidated by the experiments and CFD calculations on a 2-D small-scale combustion chamber and a 3-D large-scale wooden mock-up model. The key contributor to the compartment explosion is the transition form laminar flame to turbulent flame after the propagating flame passes through the holes between the compartments.

2. The concentration profiles on 2D small-scale chamber and 3D wooden mock-up model are successfully measured by holographic interferometry and the calibrated portable gas detector, respectively. In the 3D model, the flammable range of gasoline vapor is maintained in the range from the 1.7th day to the 175th day from the gasoline leakage.

3. The experiments on vapor diffusion process are compared with CFD results. The calculated concentration profiles on 2D small-scale chamber and 3D large-scale wooden model are tolerable agreements with the results of the experiments. Some disagreements might attribute to the convection term in CFD. 

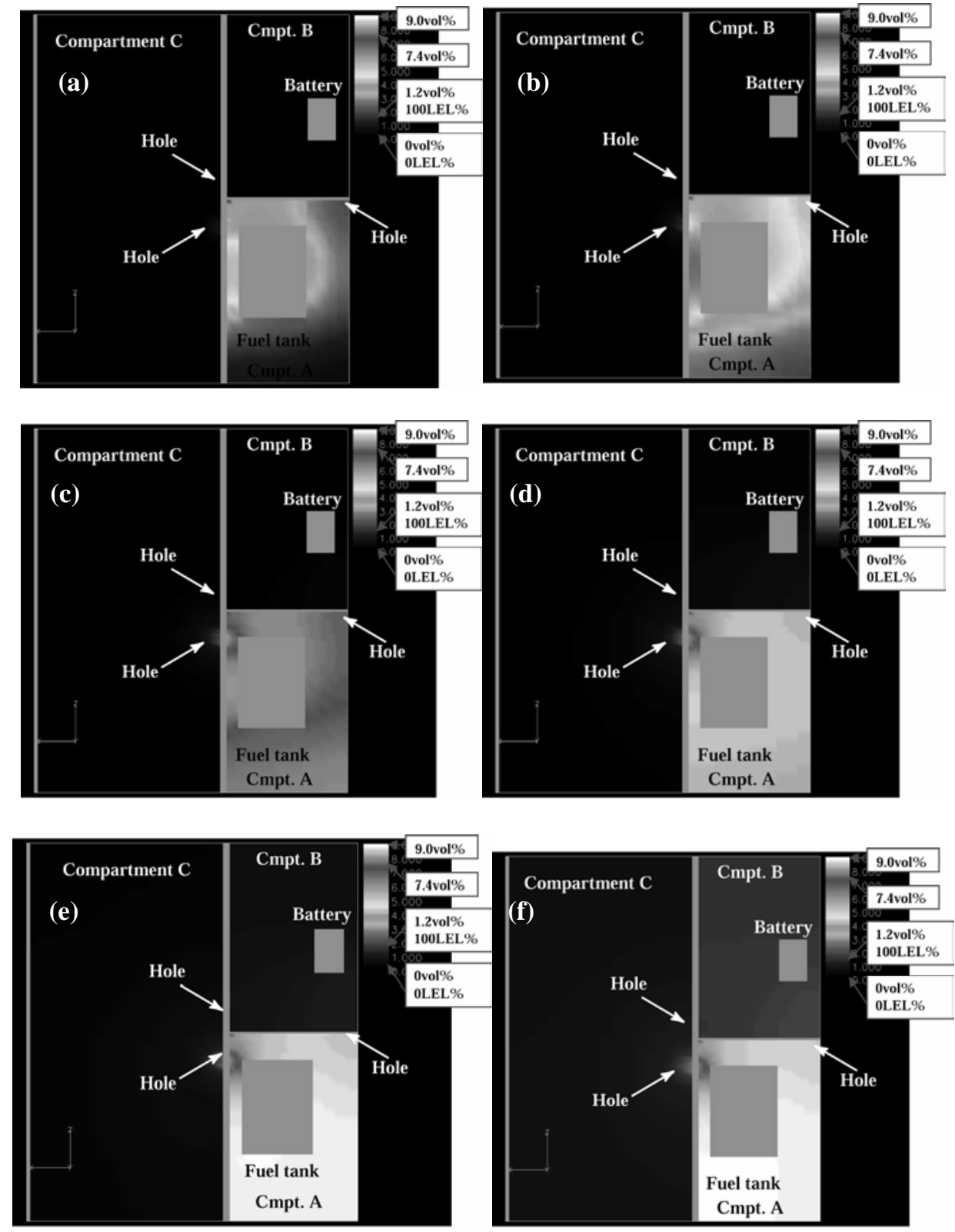

Fig. 8. Concentration profiles of CFD results at the height of $3 \mathrm{~cm}$ above the bottom board are shown after an hour from fuel-leakage (a), 2 hours (b),

6 hours (c), 12 hours (d), 24 hours (e) and 48 hours (f).

\section{ACKNOWLEDGEMENTS}

The authors thank the staffs of Oita National College of Technology, S. Naka, J. Tsuyoshi, K. Hayashi, Y. Sadakata, H. Sato, and M. Yoshikawa for their assistance in performing the experimental and CFD works. Also we acknowledge Professor Kenji Sato of Toho University for valuable discussions on a gas explosion. 


\section{REFERENCES}

[1] Fairweather, M., Hargrave, G.K., Ibrahim, S.S., and Walker, D.G., "Studies of Premixed Flame Propagation in Explosion Tubes," Combustion and Flames, 116, pp. 504-518, (1999).

[2] Razus, D., Oancea, D., Chirila, F., and Ionescu, N.I., "Transmission of an Explosion Between Linked Vessels,” Fire Safety Journa, 38, pp. 147-163 (2003).

[3] Ponizy, B., and Leyer, J.C., "Flame Dynamics in a Vented Vessel Connected to a Duct: 1. Mechanism of Vessel-duct Interaction," Combustion and Flames, 116, pp. 259-271, (1999).

[4] Wolfhard, H., Bruszak, A., "The Passage of Explosions Through Narrow Cylindrical Channels,” Combustion and Flames, 4, pp. 149-159, (1960).

[5] Girard, A., Fisson, F., and Leyer, J., "Passing of a Fame in a Cavity Drilled in the Wall of a Constant Volume Combustion Chamber," Arch Combust, 6, pp. 103-13, (1986).

[6] Starke, R., and Roth, P., "An Experimental Investigation of Flame Behavior During Explosions in Cylindrical Enclosures with Obstacles," Combustion and Flames, 75, pp. 111-121, (1989).

[7] Wolfhard, H., and Bruszak, A., "The Passage of Explosions Through Narrow Cylindrical Channels,” Combustion and Flames, 4, pp. 149-59, (1960).

[8] Phillips, H., "On the Transmission of an Explosion Through a Gap Smaller than the Quenching Distance,” Combustion and Flames, 7, pp. 129-35, (1963).

[9] Singh, J., "Gas Explosions in Interconnected Vessels: Pressure Piling,” Inst Chem Eng Symp Series, 134, pp. 195-212, (1994).

[10] Maremonti, M., Russo, G., Salzano, E., and Tufano, V., "Numerical Simulation of Gas Explosions in Linked Vessels," Journal of Loss Prevention in the Process Industries, 12, pp. 189-194, (1999).

[11] Bradley, D., Cresswell, T.M., and Puttock, J.S., "Flame Acceleration Due to Flame-induced Instabilities in Large-scale Explosions," Combustion and Flames, 124, pp. 551-559, (2001).

[12] Sochet, I., and Gillard, P., "Flammability of Kerosene in Civil and Military Aviation,” Journal of Loss Prevention in the Process Industries, 15, pp. 335-345, (2002).

[13] White, D., Beyler, C., L., Fulper, C., and Leonard, J., "Flame Spread on Aviation Fuels,” Fire Safety Journal, 28, pp. 1-31, (1997).

[14] Ito, A., Narumi, A., Konishi, T., Tashtoush, G., Saito, K., and Cremers, C.J.J., "The Measurement of Transient Two-dimensional Profiles of Velocity and Fuel Concentration Over Liquids,” Journal of Heat Transfer, 121, pp. 413-419, (1999).

[15] Konishi, T., Tashtoush, G., Ito, A., Narumi, A., and Saito, K., "Flame Spread over Liduid Fuels," Proceedings of the 28th international Symposium on Combustion, Combustion Institute, 2000, pp. 2819-2826. 
[16] Konishi, T., Ito, A., Kudo, Y., and Saito, K., "The Role of Flame Induced Liquid Surface Wave on Pulsating Flame Spread," Proceedings of the 29th

international Symposium on Combustion, Combustion Institute, 2002, pp. 267272.

[17] Konishi, T., Naka, S., Ito, A., and Saito, K., “Transient Two-dimensional Fuelconcentration Measurement Technique,” Applied Optics, 36, (33), pp. 88158819, (1997).

[18] Handbook of Japanese Industrial Standard ( $2^{\text {nd }}$ ed), Japanese Standards Association, 2002, pp.524-531. 
